\title{
Mammaglobin Gene Expression: A Superior Marker of Breast Cancer Cells in Peripheral Blood in Comparison to Epidermal-Growth-Factor Receptor and Cytokeratin-19
}

\author{
Kurt Grünewald, Margot Haun, Martina Urbanek, Michael Fiegl, \\ Elisabeth Müller-Holzner, Eberhard Gunsilius, Martina Dünser, Christian Marth, and \\ Günther Gastl
}

Division of Hematology and Oncology (KG, MH, MU, MF, EG, GG), Department of Internal Medicine, and Departments of Obstetrics and Gynecology (EMH, CM) and Surgery (MD), University of Innsbruck, Innsbruck, Austria

\begin{abstract}
SUMMARY: Various molecular markers have been used for the detection of circulating breast cancer cells in blood by reverse transcriptase-polymerase chain reaction (RT-PCR). Using nested RT-PCR, we compared the specificity and sensitivity of human mammaglobin (hMAM), epidermal-growth-factor receptor (EGF-R), and cytokeratin 19 (CK-19) expression as markers for circulating carcinoma cells in the peripheral blood of patients with breast cancer. Blood samples from 12 patients with ductal carcinoma in situ, 133 patients with invasive breast cancer, 20 patients with hematological malignancies, 31 healthy volunteers, and tumor tissues from 40 patients with invasive breast cancer were screened for mRNA encoding hMAM, EGF-R, or CK-19 by nested RT-PCR. In all breast cancer tissues, mRNA for hMAM, EGF-R, and CK-19 was detectable. In blood samples from patients with invasive breast cancer, 11 (8\%), 13 (10\%), and 64 (48\%) were positive for mRNA encoding hMAM, EGF-R, or CK-19, respectively. Blood samples from none of the healthy volunteers and patients with hematological disorders were positive for hMAM, while CK-19 mRNA was found in the blood of 12 (39\%) healthy volunteers and transcripts for EGF-R and CK-19 were detectable in $5(25 \%)$ and $2(10 \%)$, respectively, of the patients with hematological malignancies. Only hMAM mRNA expression in blood correlated with clinical parameters such as nodal status, metastasis, and CA 15-3 serum levels. In summary, hMAM transcripts detectable in blood by RT-PCR represent the most specific molecular marker for hematogenous spread of breast cancer cells. With the nested RT-PCR method, aberrant EGF-R mRNA expression might occasionally be found in hematological malignancies, whereas CK-19 mRNA expression proved to be rather nonspecific. The prognostic value of hMAM RT-PCR-based tumor cell detection in peripheral blood should be further tested and validated in prospective studies. (Lab Invest 2000, 80:1071-1077).
\end{abstract}

$D$ espite optimal surgery, adjuvant irradiation, hormonal treatment, and chemotherapy, approximately $30 \%$ of patients with localized breast cancer finally develop distant metastases. This has been attributed to early tumor seeding via the bloodstream, which is usually missed by the conventional diagnostic work-up. Identification of tumor cells in accessible peripheral tissues such as blood or bone marrow enables early detection of micrometastatic tumor cell spread. In breast cancer patients with clinically localized disease, bone marrow micrometastasis has been associated with increase in disease progression and reduced rate of survival (Diel et al, 1992; Mansi et al, 1987). Immunocytochemical screening with monoclonal antibodies against epithelial markers appears to be a reliable, albeit cumbersome, method for detecting

Received March 14, 2000

Address reprint requests to: Dr. Kurt Grünewald, Division of Hematology and Oncology, Innsbruck University Hospital, Anichstraße 35, A-6020 Innsbruck, Austria; Fax: ++43-512-504-3293 isolated carcinoma cells in blood and bone marrow (Pantel et al, 1993). In the past few years, the reverse transcriptase-polymerase chain reaction (RT-PCR) procedure has been used as a more convenient and sensitive method for the detection of circulating carcinoma cells in blood and bone marrow specimens. Human breast cancer cells commonly express various epithelial markers, such as cytokeratins, muc-1, epidermal-growth-factor receptor (EGF-R), or erbB2. However, it is difficult to make a choice among these epithelial markers for the detection of micrometastatic disease by RT-PCR because of their low specificity caused by the expression of pseudogenes and/or because of low-level illegitimate mRNA expression in hematopoietic cells. Recently, RT-PCR analysis of human mammaglobin (hMAM) gene expression was found to be a more specific tool for the detection of circulating breast cancer cells in peripheral blood (Zach et al, 1999). The hMAM gene is located on chromosome 11q12.3-13.1, a genomic region frequently amplified in breast carcinoma (Watson et al, 
1998). The hMAM gene belongs to a mammaryspecific member of the uteroglobin gene family and encodes a Mr 10.000 glycoprotein. Normally, hMAM expression is confined to the mammary gland, and overexpression was observed in $25 \%$ of primary human breast tumors (Watson and Fleming, 1996; Watson et al, 1998). Expression of hMAM mRNA in breast carcinomas, however, does not correlate with histology, tumor grade, or disease stage (Watson and Fleming, 1996; Watson et al, 1998).

In this study we compared the gene expression of hMAM with the expression of the conventionally used molecular markers, EGF-R and cytokeratin 19 (CK19), in blood samples collected from patients with localized breast cancer and patients with metastatic breast cancer. In addition, the relationship between the expression of these molecular markers and clinical characteristics was investigated.

\section{Results}

\section{Marker Expression in the Human Breast Cancer Cell Line MD-MB-361 and in Primary Breast Cancer Tissue}

The human breast cancer cell line MD-MBA-361 and tissue specimens from 40 primary invasive breast carcinomas were taken as positive controls for examining by RT-PCR the expression of hMAM, EGF-R, and CK19. In MD-MBA-361 cells and in all the tissue samples derived from primary breast carcinomas, mRNA specific for hMAM, EGF-R, and CK-19 was detectable (Table 1). To determine the detection limit for these markers, blood spiking experiments were performed. The MD-MBA-361 cell line was chosen as an arbitrary standard for human breast cancer cells. Under the conditions outlined in the "Materials and Methods" section, the detection limit for the nested RT-PCR was calculated to be one hMAM-expressing tumor cell among $10^{6}$ blood cells. The assay was comparably sensitive for the detection of hMAM, EGF-R, and CK-19 transcripts.

\section{Marker Expression in Blood Samples from Healthy Volunteers and Patients with Hematologic Malignancies}

Peripheral blood from none of the healthy volunteers contained any detectable amounts of mRNA specific for hMAM or EGF-R. However, mRNA specific for CK-19 was found in 12 (39\%) of 31 blood specimens from healthy controls. In none of the blood samples from the patients with hematological malignancies was hMAM mRNA detectable, whereas transcripts for EGF-R and CK-19 were identified in 25\% and 10\%, respectively, of those specimens (Table 1).

\section{Marker Expression in Peripheral Blood from Patients with DCIS and Invasive Breast Cancer}

Peripheral blood samples from a total of 145 patients with breast cancer were analyzed. Amplification products of hMAM, EGF-R, CK-19, and glyceraldehyde-3phosphate dehydrogenase from patients and controls are shown in Figure 1. In all 12 cases with ductal carcinoma in situ (DCIS), blood samples were negative for hMAM and EGF-R expression, whereas blood samples from 3 (25\%) of these cases contained transcripts specific for CK-19. In the peripheral blood from the remaining 133 patients with invasive breast carcinoma, 11 (8\%) specimens were positive for hMAM mRNA, whereas $13(10 \%)$ and 64 (48\%) of the specimens were positive for EGF-R or CK-19 expression, respectively. Table 1 summarizes the expression of mammaglobin, EGF-R, and CK-19 in the various patient groups and in healthy volunteers. The clinical characteristics of the 11 cases with invasive breast cancer and hMAM positivity in peripheral blood are outlined in Table 2.

\section{Correlation of Marker Expression with Clinical and Pathological Characteristics}

To investigate the relationship between the detectability of epithelial markers in peripheral blood and clinicopathological characteristics, the expression of hMAM, EGF-R, and CK-19 in blood samples was compared with histology, grading, tumor-node-metastasis (TNM)stage, estrogen and progesterone receptor expression, the current state of metastasis, and CA 15-3 levels in serum at the time of blood sampling (Table 3). EGF-R and CK-19 expression in peripheral blood did not correlate with any of these clinical or pathological features. Expression of hMAM, however, correlated significantly with the nodal status at the time of initial diagnosis $(p=0.027$ for nodal positivity; $p=0.004$ for high-risk patients with $>4$ positive axillary nodes) and the occurrence of distant metastasis $(p=0.007)$ until assaying (Fig. 2). As expected, hMAM mRNA expression was most frequent $(25 \%)$ in patients with extensive axillary lymph node involvement $(>4$ positive lymph nodes) and in cases with distant metastases

Table 1. Marker Expression in Tumor Tissue and Peripheral Blood Analyzed by Nested RT-PCR

\begin{tabular}{llrrr}
\hline & \multicolumn{1}{c}{ Clinical sample } & hMAM & EGF-R & CK-19 \\
\hline Positive controls $(n=40)$ & Breast cancer tissue & $40 / 40$ & $40 / 40$ & $40 / 40$ \\
Negative controls $(n=51)$ & Healthy volunteers (peripheral blood) & $0 / 31$ & $0 / 31$ & $12 / 31$ \\
& Hematological disorders ${ }^{a}$ (peripheral blood) & $0 / 20$ & $5 / 20$ & $2 / 20$ \\
Patients $(n=145)$ & Ductal carcinoma in situ (peripheral blood) & $0 / 12$ & $0 / 12$ & $3 / 12$ \\
& Invasive breast cancer (peripheral blood) & $11 / 133$ & $13 / 133$ & $64 / 133$ \\
\hline
\end{tabular}

RT-PCR, reverse transcriptase-polymerase chain reaction; hMAM, human mammaglobin; EGF-R, epidermal-growth-factor receptor; CK-19, cytokeratin 19.

${ }^{a}$ Blood from patients with acute lymphoblastic leukemia $(n=6)$, acute myelogenous leukemia $(n=5)$, chronic myelogenous leukemia $(n=7)$, osteomyelosclerosis $(n=1)$, and essential thrombocythemia $(n=1)$. 


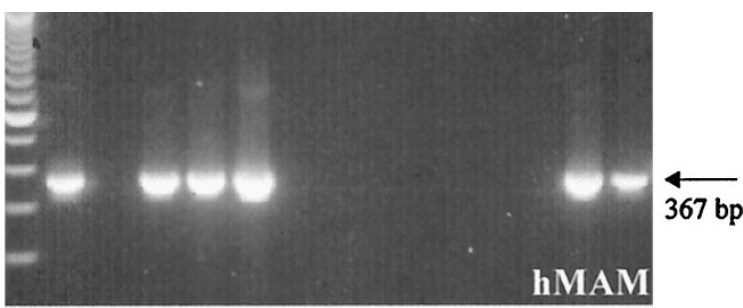

$\begin{array}{llllllllllllll}M & 1 & 2 & 3 & 4 & 5 & 6 & 7 & 8 & 9 & 10 & 11 & 12 & 13\end{array}$

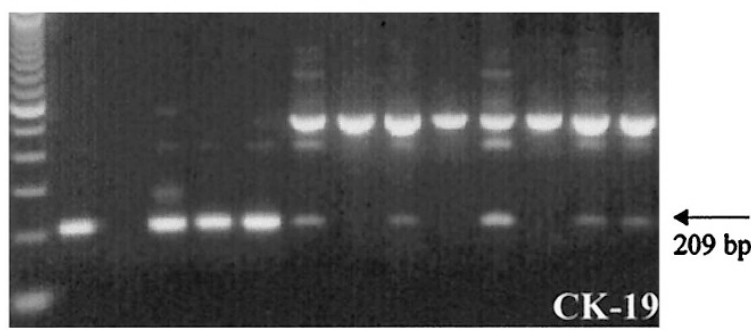

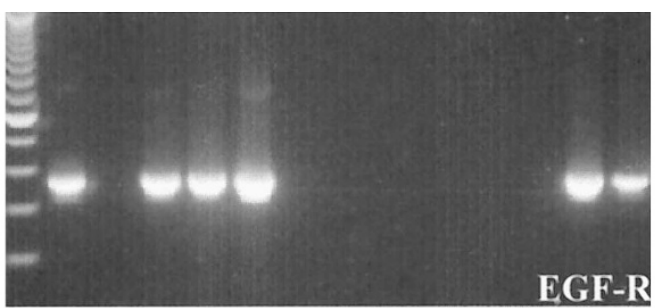

$\overleftarrow{402 \text { bp }}$
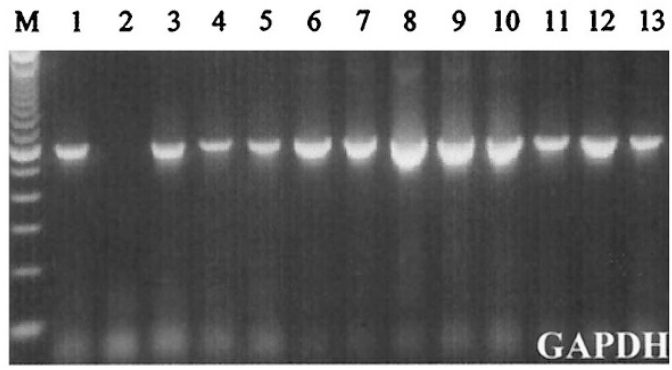

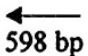

\section{Figure 1.}

Nested reverse transcriptase-polymerase chain reaction (RT-PCR) for human mammaglobin (hMAM), epidermal-growth-factor receptor (EGF-R), cytokeratin 19 (CK-19), and glyceraldehyde-3-phosphate dehydrogenase (GAPDH) in peripheral blood. M, 100 bp molecular marker; lane 1, MD-MBA-361; lane 2, negative control; lanes $3-5$, breast cancer tissue specimen; lanes $6-9$, peripheral blood from patients with hematological disorders; lanes 10 and 11 , healthy blood donors; lanes 12 and 13 , peripheral blood from patients with breast cancer.

Table 2. Characteristics of the 11 Breast Cancer Patients with hMAM Expression in Peripheral Blood

\begin{tabular}{|c|c|c|c|c|c|c|c|c|c|}
\hline Age & TNM $^{a}$ & Histology & Grade & $\mathrm{ER}$ & PR & $\begin{array}{c}\text { Distant } \\
\text { metastasis }^{b}\end{array}$ & $\begin{array}{c}\text { Blood } \\
\text { collection }^{c}\end{array}$ & $E G F-R^{d}$ & CK-19 \\
\hline 50 & pT1 pN1 M0 & Invasive ductal & II & Pos & Pos & Yes & 111 & Neg & Pos \\
\hline 56 & pT1 pN1biii M0 & Invasive ductal & III & NA & NA & No & 1 & Neg & Neg \\
\hline 58 & pT1c pNO MO & Invasive ductal & II & Pos & Pos & No & 160 & $\mathrm{Neg}$ & Pos \\
\hline 68 & pT1c pNO MO & Invasive ductal & II & Pos & Pos & No & 0 & $\mathrm{Neg}$ & Neg \\
\hline 31 & pT1c pN1 M0 & Invasive ductal & II & Neg & Neg & Yes & 18 & $\mathrm{Neg}$ & $\mathrm{Neg}$ \\
\hline 51 & pT2 pN1bii M0 & Invasive ductal & III & Neg & Neg & Yes & 70 & Neg & Neg \\
\hline 38 & pT2 pN1biii M0 & Invasive ductal & III & Neg & Neg & No & 6 & Pos & Pos \\
\hline 56 & pT2 pN1biv M0 & Invasive ductal & II & $N A$ & NA & Yes & 84 & Pos & Pos \\
\hline 50 & pT2 pN1 M0 & Invasive ductal & III & Pos & NA & Yes & 53 & $\mathrm{Neg}$ & Pos \\
\hline 43 & pT3 pN1 M0 & Invasive ductal & II & Pos & Pos & No & 5 & Neg & Pos \\
\hline 66 & pT4 pN1biii M0 & Invasive lobular & I & Pos & Pos & No & 50 & $\mathrm{Neg}$ & Pos \\
\hline
\end{tabular}

TNM, tumor-node-metastasis; ER, estrogen receptor; PR, progesterone receptor; NA, not analyzed.

${ }^{a}$ At diagnosis.

${ }^{b}$ At time of blood collection.

${ }^{c}$ Time interval since diagnosis (months).

${ }^{d}$ Detected by RT-PCR in peripheral blood.

(Fig. 2, a and b). Furthermore, hMAM expression in peripheral blood was found to correlate with CA 15-3 levels in serum (Fig. 2c). Remarkably, hMAM-positive blood samples were also found in two patients with node-negative and estrogen receptor-positive breast cancer. Expression of hMAM in the blood of breast cancer patients was not correlated with the mRNA expression for EGF-R and CK-19 .

\section{Discussion}

A recent report suggested that hMAM mRNA detection by RT-PCR in peripheral blood is a promising marker for disseminated tumor cells of breast cancer origin (Zach et al, 1999). Our cross-sectional study confirms and extends these data by comparing the expression of hMAM transcripts with other epithelial markers, such as mRNA for EGF-R and CK-19 in a larger patient cohort, and by relating the expression of hMAM in peripheral blood to clinical parameters, various patient characteristics, and conventional prognostic markers of breast cancer. Indeed, using a nested RT-PCR technique, hMAM proved to be more specific than EGF-R and CK-19. Notably, only hMAM positivity in blood was significantly correlated with nodal status, distant metastasis, and serum CA 15-3 levels. The expression of EGF-R and CK-19 in the blood of patients with breast cancer did not correlate with the expression of hMAM.

Expression of hMAM mRNA has been described in normal mammary epithelium, as well as in breast 
Table 3. Comparison of hMAM Expression in Blood and Clinical Features of the 133 Patients with Invasive Breast Cancer $^{a}$

\begin{tabular}{|c|c|c|c|}
\hline & Negative & Positive & $p$-value \\
\hline \multicolumn{4}{|l|}{ Histology } \\
\hline $\begin{array}{l}\text { Invasive ductal breast } \\
\text { cancer }\end{array}$ & 90 & 10 & \\
\hline $\begin{array}{l}\text { Non-ductal invasive breast } \\
\text { cancer }\end{array}$ & 32 & 1 & NS \\
\hline Grade I + II & 89 & 7 & \\
\hline Grade III & 25 & 4 & NS \\
\hline \multicolumn{4}{|l|}{ T-stage } \\
\hline $\mathrm{T} 1$ & 65 & 5 & \\
\hline $\mathrm{T} 2$ & 43 & 4 & \\
\hline T3 & 4 & 1 & \\
\hline T4 & 5 & 1 & NS \\
\hline \multicolumn{4}{|l|}{$\mathrm{N}$-stage } \\
\hline NO & 61 & 2 & \\
\hline $\mathrm{N} 1,2,3$ & 54 & 9 & 0.027 \\
\hline \multicolumn{4}{|l|}{$\begin{array}{l}\text { Number of positive lymph } \\
\text { nodes }\end{array}$} \\
\hline 0 & 59 & 2 & \\
\hline $1-4$ & 29 & 2 & \\
\hline$>4$ & 21 & 7 & 0.004 \\
\hline Estrogen receptor negative & 51 & 3 & \\
\hline Estrogen receptor positive & 60 & 6 & NS \\
\hline $\begin{array}{l}\text { Progesterone receptor } \\
\text { negative }\end{array}$ & 38 & 3 & \\
\hline $\begin{array}{l}\text { Progesterone receptor } \\
\text { positive }\end{array}$ & 73 & 5 & NS \\
\hline $\mathrm{CA} 15-3<30 \mathrm{U} / \mathrm{ml}^{b}$ & 93 & 3 & \\
\hline $\mathrm{CA} 15-3 \geq 30 \mathrm{U} / \mathrm{ml}$ & 9 & 2 & 0.025 \\
\hline No distant metastasis ${ }^{b}$ & 105 & 6 & \\
\hline Distant metastasis & 17 & 5 & 0.007 \\
\hline
\end{tabular}

T-stage, tumor stage; N-stage, node stage; NS, not significant.

${ }^{a}$ In a few cases not all clinical data were available.

${ }^{b}$ At the time of blood collection.

cancer cells (Watson and Fleming, 1996). In line with data from the literature, we could detect hMAM transcripts in the human breast cancer cell line, MD-MBA361 , as well as in all 40 breast carcinoma tissue specimens investigated. With the primer sets used, no aberrant mRNA transcripts of hMAM were detectable. The RT-PCR assay was not set up to measure quantitatively mRNA levels. Thus, no information on the extent of marker expression in the breast cancer cell line, tumor tissue, or blood cells can be obtained from this analysis. The detection limit for circulating tumor cells in peripheral blood was one tumor cell per $10^{6}$ mononuclear blood cells for MD-MBA-361 cells. The nested RT-PCR assays proved to be comparably sensitive for the detection of mRNA for hMAM, EGF-R, and CK-19 in peripheral blood. The sensitivity of the assay ranged from 1 to 10 tumor cells among $10^{6}$ blood cells. At this sensitivity level, transcripts for hMAM were invariably absent in blood samples from healthy donors, patients with hematological malignancies, or DCIS of the breast.
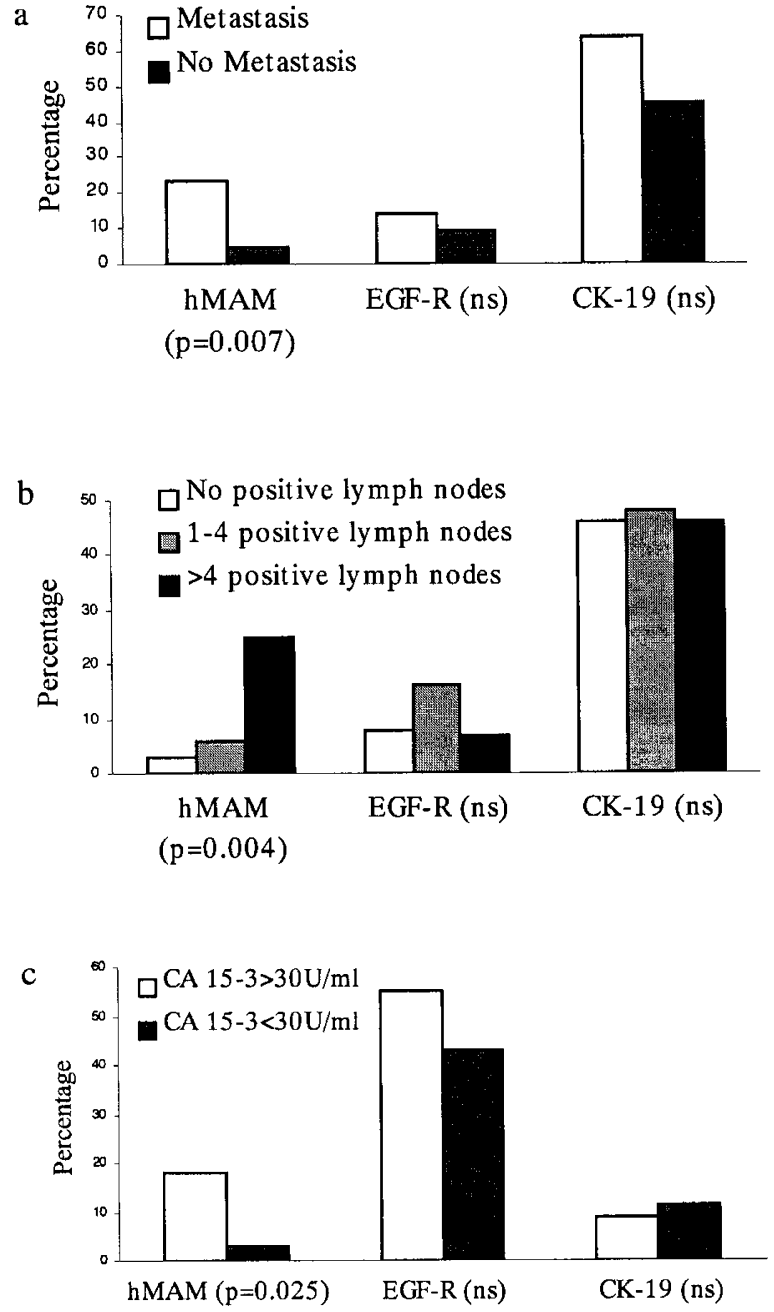

Figure 2.

Relationships between hMAM mRNA expression in peripheral blood and (a) the state of metastasis at the time of blood collection, (b) the nodal status at the time of diagnosis, and (c) CA 15-3 serum levels at the time of blood collection.

In contrast to hMAM mRNA, transcripts for EGF-R and CK-19 detected in the blood by nested RT-PCR are of questionable relevance because of their high rate of false positivity. In fact, EGF-R and CK-19 transcripts were detectable in $25 \%$ and $10 \%$, respectively, of patients with hematological malignancies, and CK-19 was found to be expressed in 39\% of healthy volunteers. These findings suggest that expression of mRNA for EGF-R and CK-19 is not specific for epithelial cell tissues.

To establish a specific nested RT-PCR assay for the detection of CK-19 mRNA, specific primer pairs were selected for excluding the amplification of CK-19 pseudogenes (Kruger et al, 1996). Despite the use of such primers, a rather high rate (39\%) of CK-19 mRNA positivity was found in blood samples from healthy controls. These findings are in agreement with data from other investigators reporting detectable CK-19 transcripts in up to $78 \%$ of peripheral blood samples taken from healthy volunteers or patients without carcinoma (Bostick et al, 1998; Burchill et al, 1995; 
Datta et al, 1994; Krismann et al, 1995). This high rate of false positivity might be caused primarily by the high sensitivity of the nested RT-PCR assay picking up illegitimate low-level expression of CK-19 in mononuclear blood cells (Chelly et al, 1989; Eltahir et al, 1998; Schoenfeld et al, 1994).

So far, EGF-R-specific transcripts have not been detected in human blood mononuclear cells. Because EGF-R mRNA was not detectable in blood samples from healthy volunteers and patients with DCIS, positivity for EGF-R expression in five (25\%) of the 20 peripheral blood samples from hematological malignancies (three cases of chronic myelogenous leukemia, one case of osteomyelosclerosis, and one case of essential thrombocythemia) is most likely caused by aberrant expression of the EGF-R gene in malignant hematopoietic cells.

Among the molecular markers tested, only hMAM mRNA expression in blood correlated significantly with established prognostic factors, such as axillary lymph node involvement, distant metastasis, and elevated CA 15-3 serum levels. The incidence of hMAM mRNA positivity in blood was equally high (25\%) in patients with more than four axillary lymph nodes involved at the time of diagnosis and in patients with distant metastases at the time of assaying. Among 114 patients with breast cancer who were analyzed by Zach et al (1999), a higher percentage had detectable levels of hMAM mRNA in peripheral blood (28\% at the time of diagnosis, $6 \%$ of patients with nonmetastatic disease, and $49 \%$ of the patients with distant metastases at the time of assaying). Their higher rate of hMAM positivity in blood might be attributable to the time of blood sampling and different patient characteristics, perioperative blood collection, and inclusion of patients with more advanced metastatic disease. In our study, hMAM positivity in blood was significantly correlated with node-positive or metastatic breast cancer and was seen only in two patients with nodenegative tumors. The prognostic relevance of hMAM positivity in blood samples of node-negative patients with otherwise good prognosis remains to be determined in larger patient populations. Although DCIS lesions can strongly express hMAM (Watson et al, 1999), all 12 patients with DCIS were found to be negative for hMAM in blood. This finding is in keeping with the clinical experience that DCIS does not metastasize.

Several investigators have reported a significant correlation between tumor cell detection in the peripheral blood of patients with breast cancer and prognosis for a relapse-free future and overall survival (Pantel et al, 1999). The detectability of circulating breast cancer cells following surgery and adjuvant therapy could then become a surrogate marker for micrometastatic spread and an early indicator of disease progression. Large retrospective, as well as prospective, studies are needed to validate these findings. To evaluate the prognostic impact of hMAM expression in blood, a prospective study has been launched at our institution.

\section{Materials and Methods}

\section{Patients and Healthy Control Subjects}

With informed consent, $10 \mathrm{ml}$ of blood was drawn from patients with invasive breast cancer or DCIS. Blood was collected either at the time of diagnosis ( $n=25$ ) or later during follow-up $(n=120)$. As controls, blood samples were taken from patients with hematological disorders and from healthy volunteers. In addition, tissue samples from primary breast carcinomas were included as a positive control. The patients' characteristics are summarized in Table 4. Patients with a history of, or the simultaneous presence of, a second malignancy were excluded. The majority of patients with breast cancer had undergone surgery between 1980 and 1999 at the Departments of Obstetrics and Gynecology or General Surgery at the University Hospital Innsbruck, Austria. Surgical treatment consisted of modified radical mastectomy or breast conserving surgery with axillary lymph node dissection. A median number of 20 (range, 10-40) axillary lymph nodes was examined. All patients with involved lymph nodes or high-risk node negative breast cancer received adjuvant chemotherapy.

Table 4. Clinical Features of Patients with Invasive Breast Cancer $^{a}$

\begin{tabular}{lc}
\hline \multicolumn{1}{c}{ Clinical features } & N (\%) ${ }^{b}$ \\
\hline Premenopausal & $45(34)$ \\
Postmenopausal & $88(66)$ \\
Primary treatment & \\
$\quad$ Mastectomy & $66(50)$ \\
$\quad$ Breast conserving therapy & $62(48)$ \\
$\quad$ No surgery & $3(2)$ \\
Adjuvant chemotherapy & $60(46)$ \\
Palliative chemotherapy & $10(8)$ \\
No chemotherapy & $60(46)$ \\
Adjuvant hormonal treatment & $51(44)$ \\
No hormonal treatment & $66(56)$ \\
Adjuvant radiotherapy & $73(66)$ \\
No radiotherapy & $38(34)$ \\
Stage & \\
$\quad$ T1 & $70(56)$ \\
T2 & $43(35)$ \\
T $>$ 2 & $11(9)$ \\
Nodal status & \\
N0 & $63(51)$ \\
N + & $60(49)$ \\
Estrogen receptor positive & $66(55)$ \\
Estrogen receptor negative & $54(45)$ \\
Progesteron receptor positive & $78(66)$ \\
Progesteron receptor negative & $41(34)$ \\
Grade 1 + 2 & $96(77)$ \\
Grade 3 & $28(23)$ \\
Distant metastasis (at time of blood & $28-82$. \\
No distant metastasis (at time of blood &
\end{tabular}




\section{Cell Line}

The breast cancer cell line MD-MBA-361 (Cailleau et al, 1978) was taken as positive control for the expression of hMAM, EGF-R, and CK-19, as well as for sensitivity testing of the RT-PCR assays.

\section{RNA Extraction and CDNA}

Total cellular RNA was extracted from the MDA-MB361 cell line, tumor tissue, and mononuclear peripheral blood cells by using RNA-clean (AGS $\mathrm{GmbH}$, Heidelberg, Germany) according to the manufacturer's instructions and dissolved in diethylpyrocarbonatetreated water. RNA concentration was measured spectrophotometrically at $260 \mathrm{~nm}$ and the RNA samples were stored at $-70^{\circ} \mathrm{C}$ until assaying. First-strand cDNA was synthesized by using Moloney-murine leukemia virus (M-MLV) reverse transcriptase (Life Technologies, Vienna, Austria). RNA (1 $\mu \mathrm{g})$ was added to 200 units of enzyme, $2 \mu \mathrm{l} 10 \times$ reaction buffer $(500 \mathrm{~mm}$ Tris $\mathrm{HCl}, \mathrm{pH}$ 8.3; $750 \mathrm{~mm} \mathrm{KCl} ; 100 \mathrm{~mm}$ DTT; $30 \mathrm{~mm} \mathrm{MgCl}$ ), $1 \mathrm{~mm}$ deoxyribonucleoside triphosphates (Amersham Pharmacia Biotech, Piscataway, New Jersey), 20 units RNAsin (Promega Cooperation, Madison, Wisconsin), $5 \mu \mathrm{M}$ random hexamers (Roche Diagnostics, Mannheim, Germany), and $1 \mu \mathrm{M}$ antisense primer to a final volume of 20 $\mu$ l. The cDNA synthesis was performed at $37^{\circ} \mathrm{C}$ for 60 minutes. After heat inactivation at $95^{\circ} \mathrm{C}$ for 10 minutes, $2 \mu \mathrm{l} \mathrm{cDNA}$ were subjected to PCR analysis.

\section{PCR and Gel Electrophoresis}

Specific cDNA sequences were amplified in a reaction mix composed of $2 \mu \mathrm{l}$ cDNA, $5 \mu \mathrm{l} 10 \times$ PCR-buffer (100 mm Tris HCl, $\mathrm{pH} 8.3 ; 500 \mathrm{~mm} \mathrm{KCl;} 15$ mm MgCl , $0.1 \%$ gelatin), $50 \mu \mathrm{m}$ dNTPs, $400 \mathrm{~nm}$ each of specific sense and antisense primer, and 1.5 units AmpliTaq DNA polymerase (Perkin Elmer, Vienna, Austria) in a total volume of $50 \mu \mathrm{l}$. The second round of PCR, using nested primer and $1 \mu$ l of outers product, was performed identically, except that the dNTP concentra- tion was increased to $800 \mathrm{~nm}$. All primers were synthesized at the MWG-Biotech laboratory (Ebersberg, Germany). The primer sequences and the specific annealing temperatures are listed in Table 5. The cycling conditions for glyceraldehyde-3-phosphate dehydrogenase, EGF-R, or hMAM were 40 cycles (30 seconds at $95^{\circ} \mathrm{C}, 60$ seconds at annealing tempera-

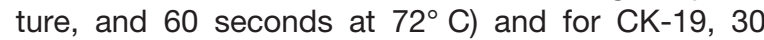
cycles (30 seconds at $95^{\circ} \mathrm{C}, 60$ seconds at annealing temperature, and 90 seconds at $72^{\circ} \mathrm{C}$ ). As the first step of the PCR reaction, samples were heated up to $95^{\circ} \mathrm{C}$ for 3 minutes. At the end of all PCR runs, a last extension was done at $72^{\circ} \mathrm{C}$ for 5 minutes. The RT-PCR products were analyzed in $2 \%$ agarose gels stained with ethidium bromide. A 100 bp DNA ladder (Life Technologies) was used as a size marker. The presence of intact RNA was confirmed by a singleround RT-PCR using the housekeeping gene glyceraldehyde-3-phosphate dehydrogenase. A DNAderived amplification product of $\mathrm{CK}-19$ PCR is approximately $500 \mathrm{bp}$ in length and could be clearly distinguished from the RNA-derived product. The presence of cellular DNA in the RNA preparation influenced neither the sensitivity nor the specificity of the CK-19 assay. As a positive control, RNA extracted from the MD-MBA-361 cell line was taken, and negative controls contained all components of RT-PCR reaction, but no target RNA template. For testing the sensitivity of the different RT-PCR assays, RNA from peripheral blood cells was mixed with decreasing amounts of RNA isolated from the MD-MBA-361 cell line. To verify the specificity of the RT-PCR products, Southern blot hybridizations with specific DNA probes were performed (data not shown).

\section{Statistical Analysis}

Data were analyzed by means of nonparametric tests. Median, rank, and quartiles are given for characterization of parameters. Differences in characteristics and of groups were analyzed by the two-tailed chi-square

Table 5. Primer Sequences for RT-PCR, Including Length of Expected PCR-Product and the Specific Annealing Temperature (Tm) for Each Primer Pair

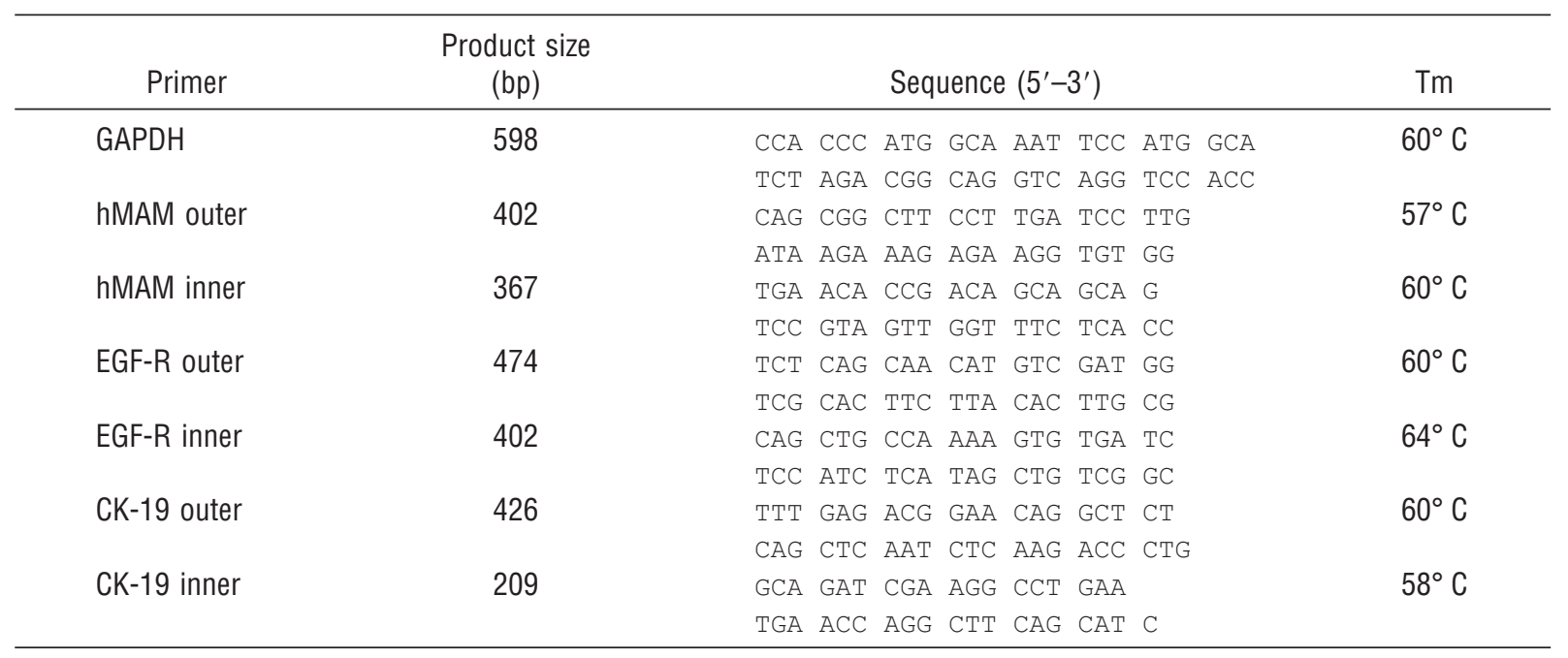


or Fisher's exact test, when appropriate. The Wilcoxon's rank sum test was used to compare medians. A p value of less than 0.05 was considered as significant. Data processing was performed by means of SPSS for Windows (SPSS Inc., Chicago, Illinois).

\section{Acknowledgements}

This work was supported by the "Tiroler Verein zur Förderung der Krebsforschung" and by the "Verein zur Förderung von Forschung und Fortbildung in molekularer Genetik und Diagnostik internistischer Erkrankungen."

\section{References}

Bostick PJ, Chatterjee S, Chi DD, Huynh KT, Giuliano AE, Cote R, and Hoon DS (1998). Limitations of specific reversetranscriptase polymerase chain reaction markers in the detection of metastases in the lymph nodes and blood of breast cancer patients. J Clin Oncol 16:2632-2640.

Burchill SA, Bradbury MF, Pittman K, Southgate J, Smith B, and Selby $P$ (1995). Detection of epithelial cancer cells in peripheral blood by reverse transcriptase-polymerase chain reaction. Br J Cancer 71:278-281.

Cailleau R, Olive M, and Cruciger QV (1978). Long-term human breast carcinoma cell lines of metastatic origin: Preliminary characterization. In Vitro 14:911-915.

Chelly J, Concordet JP, Kaplan JC, and Kahn A (1989). Illegitimate transcription: Transcription of any gene in any cell type. Proc Natl Acad Sci USA 86:2617-2621.

Datta YH, Adams PT, Drobyski WR, Ethier SP, Terry VH, and Roth MS (1994). Sensitive detection of occult breast cancer by the reverse-transcriptase polymerase chain reaction. $\mathrm{J}$ Clin Oncol 12:475-482.

Diel IJ, Kaufmann M, Goerner R, Costa SD, Kaul S, and Bastert $G$ (1992). Detection of tumor cells in bone marrow of patients with primary breast cancer: A prognostic factor for distant metastasis. J Clin Oncol 10:1534-1539.

Eltahir EM, Mallinson DS, Birnie GD, Hagan C, George WD, and Purushotham AD (1998). Putative markers for the detection of breast carcinoma cells in blood. Br J Cancer 77:12031207.

Krismann M, Todt B, Schroder J, Gareis D, Muller KM, Seeber S, and Schutte J (1995). Low specificity of cytokeratin 19 reverse transcriptase-polymerase chain reaction analyses for detection of hematogenous lung cancer dissemination. J Clin Oncol 13:2769-2775.
Kruger W, Krzizanowski C, Holweg M, Stockschlader M, Kroger N, Jung R, Mross K, Jonat W, and Zander AR (1996). Reverse transcriptase/polymerase chain reaction detection of cytokeratin-19 mRNA in bone marrow and blood of breast cancer patients. J Cancer Res Clin Oncol 122:679-686.

Mansi JL, Berger U, Easton D, McDonnell T, Redding WH, Gazet JC, McKinna A, Powles TJ, and Coombes RC (1987). Micrometastases in bone marrow in patients with primary breast cancer: Evaluation as an early predictor of bone metastases. Br Med J (Clin Res Ed) 295:1093-1096.

Pantel K, Schlimok G, Braun S, Kutter D, Lindemann F, Schaller G, Funke I, Izbicki JR, and Riethmuller G (1993). Differential expression of proliferation-associated molecules in individual micrometastatic carcinoma cells. J Natl Cancer Inst 85:1419-1424.

Pantel K, Cote RJ, and Fodstad O (1999). Detection and clinical importance of micrometastatic disease. J Natl Cancer Inst 91:1113-1124.

Schoenfeld A, Luqmani Y, Smith D, O'Reilly S, Shousha S, Sinnett HD, and Coombes RC (1994). Detection of breast cancer micrometastases in axillary lymph nodes by using polymerase chain reaction. Cancer Res 54:2986-2990.

Watson MA, Darrow C, Zimonjic DB, Popescu NC, and Fleming TP (1998). Structure and transcriptional regulation of the human mammaglobin gene, a breast cancer associated member of the uteroglobin gene family localized to chromosome 11q13. Oncogene 16:817-824.

Watson MA, Dintzis S, Darrow CM, Voss LE, DiPersio J, Jensen R, and Fleming TP (1999). Mammaglobin expression in primary, metastatic, and occult breast cancer. Cancer Res 59:3028-3031.

Watson MA and Fleming TP (1996). Mammaglobin, a mammary-specific member of the uteroglobin gene family, is overexpressed in human breast cancer. Cancer Res 56:860865.

Zach O, Kasparu H, Krieger O, Hehenwarter W, Girschikofsky $M$, and Lutz D (1999). Detection of circulating mammary carcinoma cells in the peripheral blood of breast cancer patients via a nested reverse transcriptase polymerase chain reaction assay for mammaglobin mRNA. J Clin Oncol 17: 2015-2019. 